\title{
Finnish upper limb-onset distal myopathy
}

INSERM

\section{Source}

INSERM. (1999). Orphanet: an online rare disease and orphan drug data base. Finnish upper limb-onset distal myopathy. ORPHA:399086

Finnish upper limb-onset distal myopathy is a rare, genetic distal myopathy characterized by slowly progressive distal to proximal limb muscle weakness and atrophy, with characteristic early involvement of thenar and hypothenar muscles. Patients present with clumsiness of the hands and stumbling in the fourth to fifth decade of life, and later develop steppage gait and contractures of the hands. Progressive fatty degeneration affects intrinsic muscles of the hands, gluteus medium and both anterior and posterior compartment muscles of the distal lower extremities, with later involvement of forearm muscles, triceps, infraspinatus and the proximal lower limb muscles. Asymmetry of muscle involvement is common. 